\title{
Hydrophilic di- and tripeptides are not a precondition for savoury flavour in mature Cheddar cheese
}

\author{
Lene T. ANDERSEN ${ }^{1}$, Hedwig SCHLICHTHERLE-CERNY ${ }^{2}$, Ylva ARDö ${ }^{1 *}$ \\ ${ }^{1}$ Department of Food Science, University of Copenhagen, 1958 Frederiksberg, Denmark \\ ${ }^{2}$ Agroscope Liebefeld-Posieux Research Station ALP, 3003 Bern, Switzerland
}

\begin{abstract}
In the literature hydrophilic glutamyl di- and tripeptides have been described to induce an umami or savoury taste. In this study, HILIC-ESI-MS was applied for analysis of lowmolecular-weight peptides in the ultra-filtrated (cut-off $10 \mathrm{~kg} \cdot \mathrm{mol}^{-1}$ ) water-soluble extract of two mature Cheddar cheeses, selected because of their pronounced savoury flavour. A reference mixture of amino acids and di- and tripeptides was successfully separated by HILIC using ammonium acetate buffer $\left(0.50 \mathrm{~g} \cdot \mathrm{L}^{-1}, \mathrm{pH} 5.5\right)$ as the mobile phase. Unambiguous identification of the compounds was based on retention time and characteristic fragmentation patterns in MS/MS and $\mathrm{MS}^{3}$. However, no low-molecular-weight glutamyl peptides were identified in the extracts of the mature Cheddar cheeses. It was concluded that hydrophilic glutamyl di-and tripeptides are not a precondition for savoury flavour in mature Cheddar cheese.
\end{abstract}

savoury / umami / Cheddar / hydrophilic peptide

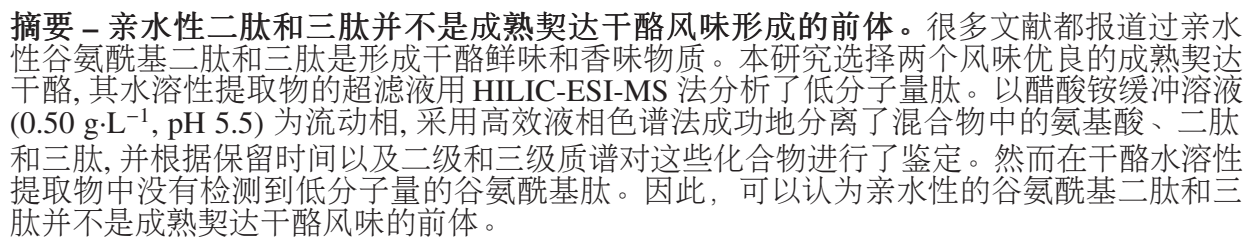

香味 / 鲜味 / 契达干酪 / 亲水性肽

Résumé - Les di- et tripeptides hydrophiles ne sont pas pré-requis pour obtenir une flaveur savoureuse du Cheddar affiné. Dans la littérature, les di- et tripeptides à glutamine ont été décrits comme induisant un goût umami ou savoureux. Dans cette étude, nous avons analysé par chromatographie liquide à interaction hydrophile (HILIC) couplée à la spectrométrie de masse (ESI-MS) les peptides de faible poids moléculaire présents dans l'ultrafiltrat (seuil de coupure $10 \mathrm{~kg} \cdot \mathrm{mol}^{-1}$ ) d'extrait aqueux de deux Cheddar affinés, sélectionnés en raison de leur flaveur savoureuse prononcée. Un mélange de référence d'acides aminés et de di- et tripeptides a été séparé avec succès par HILIC en utilisant un tampon d'acétate d'ammonium $\left(0,50 \mathrm{~g} \cdot \mathrm{L}^{-1}, \mathrm{pH} 5,5\right)$ comme phase mobile. L'identification des composés a été réalisée sans ambigüité d'après leurs temps de rétention et leurs profils

$\overline{* \text { Corresponding author }}$ (通讯作者): ya@life.ku.dk 
de fragmentation caractéristiques en MS/MS et $\mathrm{MS}^{3}$. Cependant, aucun peptide à glutamine de faible poids moléculaire n'a été identifié dans les extraits de Cheddar affiné. Nous en avons conclu que les di- et tripeptides à glutamine hydrophiles ne pré-conditionnent pas la flaveur savoureuse du Cheddar affiné.

savoureux / umami / Cheddar / peptide hydrophile

\section{INTRODUCTION}

During cheese ripening, proteolysis of casein forms the basis for generating a wide range of peptides and amino acids, with the potential to influence cheese taste. An equilibrated balance between proteolysis and peptidolysis is needed to prevent development of bitterness and to obtain a general background flavour with a brothy and savoury taste $[6,12]$. For Cheddar cheese the diafiltrated water-soluble extract (cut-off $10 \mathrm{~kg} \cdot \mathrm{mol}^{-1}$ ) has been described as savoury $[4,7,9,21]$. Umami, the Japanese word for savoury or delicious, is an important sensory taste attribute for mature Cheddar cheese because of the naturally high content of amino acids, and especially Glu [14]. However, the complexity of the taste indicates contribution from other components in Cheddar cheese to this sensation. Organic acids and salts have been identified as potent taste compounds or taste enhancers in relation to umami and savoury in general [8, $20,25]$. With regard to peptides, special attention has been paid to the taste contribution of hydrophilic di- and tripeptides. In particular, those containing Glu have been described as having an umami or savoury taste $[2,15,16,23]$. However, the taste properties of these peptides are discussed controversially by Van den Oord and van Wassenaar [24]. In relation to cheese, only a few low-molecular-weight peptides have been identified [13, 17-19].

Reversed-phase high-performance liquid chromatography (RP-HPLC) is a powerful separation technique for peptides in cheese extracts [3]. However, small hydrophilic peptides are not retained in the hydrophobic stationary phase but elute in the void volume. As an alternative, hydrophilic interaction liquid chromatography (HILIC) coupled to electrospray ionisation mass spectrometry (ESI-MS) could be used for analysis of small hydrophilic peptides. The separation mechanism of HILIC is based on the solubility of the analytes in the water-enriched layer in a hydrophilic stationary phase and in a relatively more hydrophobic mobile phase. Thus, the retention time increases with the hydrophilicity of the compound, and the observed elution order will be approximately the opposite of RP-HPLC [1]. As reviewed by Hemstrom and Irgum [11], HILIC has been used for a number of applications within separation of, e.g., carbohydrates, amino acids, peptides and proteins. In relation to complex food systems glutamyl dipeptides have been successfully identified in a wheat gluten hydrolysate and an extract of Parmesan cheese using HILIC as a separation technique [19].

The objective of this study was to reveal the presence of umami tasteactive hydrophilic di- and tripeptides with the potential to explain a pronounced savoury flavour in mature Cheddar cheese. HILIC-ESI-MS was applied for analysis of these hydrophilic low-molecular-weight peptides in Cheddar cheese.

\section{MATERIALS AND METHODS}

\subsection{Reference mixture of amino acids and peptides}

The reference mixture for HILIC-MS contained acidic, basic, hydrophilic uncharged and hydrophobic amino acids, 
and di- and tripeptides. The amino acids Leu, Val, Pro, Glu, Asp, Ser, Asn, Arg and Lys were purchased from Merck (Darmstadt, Germany), Fluka (Buchs, Switzerland) and Sigma-Aldrich (St. Louis, MO, USA), and the di- and tripeptides Trp-Gly-Tyr, Glu-Ala, AlaGlu, Gly-Glu, Thr-Glu, Glu-Asp, Asp-Glu, Glu-Ser, Glu-Glu-Glu and Arg-Lys were purchased from Bachem (Bubendorf, Switzerland). The amino acids and peptides were dissolved in acetonitrile/water (60:40) and analysed at a concentration of $0.5 \mathrm{~g} \cdot \mathrm{L}^{-1}$ and $0.25 \mathrm{~g} \cdot \mathrm{L}^{-1}$, respectively. The mixture supplemented with Ser-Glu, Gly-Glu, Glu-Thr and Glu-Glu (Bachem, Bubendorf, Switzerland) is referred to as the extended reference mixture.

\subsection{Extract of Cheddar cheese}

Two commercially available mature Cheddar cheeses with pronounced savoury flavour were selected for these experiments by professional cheese graders. Cheese A was from Australia, aged 12 months, and cheese B was from Ireland, aged 10 months. The latter contained a thermophilic Lactobacillus strain as adjunct culture. The water-soluble fraction was obtained by mixing grated cheese with Milli-Q water at a ratio of $1: 2(\mathrm{w} / \mathrm{w})$ and homogenising the slurry using a mixer (Ultra Turrax, Staufen, Germany, $2 \times 1$ min at $13500 \mathrm{rpm}$ with $1 \mathrm{~min}$ suspension in between). The homogenate was stirred for $1 \mathrm{~h}$ at $40{ }^{\circ} \mathrm{C}$ and centrifuged for $45 \mathrm{~min}$ at $4{ }^{\circ} \mathrm{C}$ at $38720 \times \mathrm{g}$. The watersoluble extract was filtered through glass wool and filter paper (Whatman No. 42, Maidstone, UK) and ultra-filtrated using an Amicon cell (Amicon, Danvers, MA, USA) with a regenerated cellulose membrane with a molecular weight cut-off of $10 \mathrm{~kg} \cdot \mathrm{mol}^{-1}$ (Millipore Inc., Milford, MA, USA). The solutions were freeze-dried and stored at $-20{ }^{\circ} \mathrm{C}$ until use. Before analysis the samples were redissolved in water (40 mg $\cdot \mathrm{mL}^{-1}$ ). This corresponded to $0.46 \mathrm{~g}$ cheese $\cdot \mathrm{mL}^{-1}$ and $0.35 \mathrm{~g}$ cheese $\cdot \mathrm{mL}^{-1}$ for cheese $\mathrm{A}$ and $\mathrm{B}$, respectively. The ultrafiltrated water-soluble extracts were tasted to ensure that a savoury flavour remained.

\subsection{HILIC-ESI-MS}

The HILIC separation was performed using two commercially available HILIC columns, HILIC Column 1 (TSKgel Amide-80, $2.0 \mathrm{~mm}$ i.d. $\times 1.0 \mathrm{~cm}$ guard column and $1 \mathrm{~mm}$ i.d. $\times 25.0 \mathrm{~cm}, 5 \mu \mathrm{m}$, from Tosoh Bioscience, Tokyo, Japan) and HILIC Column 2 (ZIC-HILIC, $1.0 \mathrm{~mm}$ i.d. $\times 5.0 \mathrm{~mm}$ guard column and $1 \mathrm{~mm}$ i.d. $\times 15.0 \mathrm{~cm}, 3.5 \mu \mathrm{m}$, from SeQuant, Umeå, Sweden). The LC system consisted of a quaternary pump (Rheos 2200, Flux Instruments, Basel, Switzerland) in combination with a PAL HTS autosampler (CTC Analytics, Zwingen, Switzerland). Five $\mu \mathrm{L}$ of the reference mixture and $10 \mu \mathrm{L}$ of the water-soluble cheese extracts were injected.

A LTQ ion trap mass spectrometer (Thermo, Waltham, MA, USA) equipped with an ESI source was used for the mass spectrometry analysis. Nitrogen was used as sheath gas; the capillary temperature was $250{ }^{\circ} \mathrm{C}$ and the spray voltage $4 \mathrm{kV}$. The $\mathrm{MS}^{\mathrm{n}}$ spectra were obtained at a relative collision energy of $30 \%$ in the data-dependent scan mode with the signal threshold triggering a further MS step set to $2.5 \cdot 10^{5}$. Data acquisition and processing were carried out using the Xcalibur software version 2.0 SR2 (Thermo, Waltham, MA, USA).

A solution of caffeine, the peptide Met-Arg-Phe-Ala and Ultramark 1621 (Thermo, Waltham, MA, USA) was used for calibration according to the manufacturer's recommendations. Tuning of the instrument in the positive ionisation mode was performed using a solution 
(acetonitrile/water, 60:40) containing the peptide Glu-Asp (0.25 g. $\left.\mathrm{L}^{-1}, \mathrm{M}_{\mathrm{W}} 262.2\right)$. The mobile phase system used for HILICESI-MS was ammonium acetate buffer $\left(0.50 \mathrm{~g} \cdot \mathrm{L}^{-1}, \mathrm{pH} 5.5\right)$ in acetonitrile/water (90:10) as solvent $\mathrm{A}$ and ammonium acetate buffer $\left(0.50 \mathrm{~g} \cdot \mathrm{L}^{-1}, \mathrm{pH} 5.5\right)$ in acetonitrile/water (60:40) as solvent $\mathrm{B}$. The ammonium acetate buffer was prepared from a stock solution of ammonium acetate $\left(50.1 \mathrm{~g} \cdot \mathrm{L}^{-1}\right)$, which had been adjusted to $\mathrm{pH} 5.5$ by acetic acid $\left(39.0 \mathrm{~g} \cdot \mathrm{L}^{-1}\right)$. The gradient was 13 to $40 \%$ water in $90 \mathrm{~min}$ and $40 \%$ water in 10 min with a flow of $0.05 \mathrm{~mL} \cdot \mathrm{min}^{-1}[19,22]$.

\section{RESULTS AND DISCUSSION}

\subsection{Separation of amino acids and peptides in a reference mixture}

The amino acids and hydrophilic diand tripeptides in the reference mixture were successfully analysed by HILIC-ESIMS (Fig. 1). The performance of the two HILIC columns was evaluated by their ability to separate the individual compounds in the reference mixture. Retention of the amino acids and the peptides were obtained on both HILIC columns and the elution order was similar (data not shown).

Among the amino acids, the hydrophobic Leu and Val eluted first, followed by Pro and the hydrophilic, uncharged Ser and Asn, which coeluted from HILIC Column 2. Then the acidic amino acids Asp and Glu coeluted, as observed for both HILIC columns. The positively-charged amino acids Arg and Lys were retained longest. Specifically for HILIC Column 1, tailing was observed for these two compounds, possibly due to ion interactions with the stationary phase $[10,11]$. The potentially taste-active hydrophilic glutamyl peptides eluted in the order Glu-Ala, ThrGlu, Glu-Ser, Ala-Glu, Gly-Glu, Glu-Asp and Asp-Glu. The more hydrophilic GluGlu-Glu was retained longest. Separation of the isobaric pair Glu-Ala and Ala-Glu was obtained on both HILIC columns, whereas Glu-Asp and Asp-Glu were only partly separated on HILIC Column 2. The elution profile of the reference mixture on HILIC Column 2 is shown in Figure 1.

The observed sequence-specific elution of the isobaric glutamyl peptides, where the peptide with the N-terminal glutamyl residue eluted prior to its reversed analogue, is in accordance with earlier observations $[1,19]$. Unambiguous identification of the peptides was possible by using MS/MS and MS $^{3}$ spectra as described in Section 3.2.

In relation to the potentially umami taste-active peptides it was important to obtain the best separation and identification conditions for the pairs of isobaric glutamyl peptides. To further evaluate the HILIC columns' ability to separate these compounds, the reference mixture was completed with Ser-Glu, Glu-Gly and GluThr. The additional pairs of isobaric peptides were all baseline separated by HILIC Column 2, whereas the separation ability for HILIC Column 1 was limited (data not shown).

On the background of these results it was concluded that the hydrophilic glutamyl peptides of interest for savoury flavour were best separated on HILIC Column 2, which was used for the analysis of the water-soluble extract of the mature Cheddar cheeses.

\subsection{Identification of isobaric glutamyl peptides by mass spectrometry}

Isobaric pairs of peptides give rise to identical ions $(\mathrm{m} / \mathrm{z})$ in full-scan mass spectra. Identification was therefore based on the comparison of retention times, and MS/MS and $\mathrm{MS}^{3}$ spectra with those of reference compounds. Reverse analogue peptides exhibit different fragmentation 

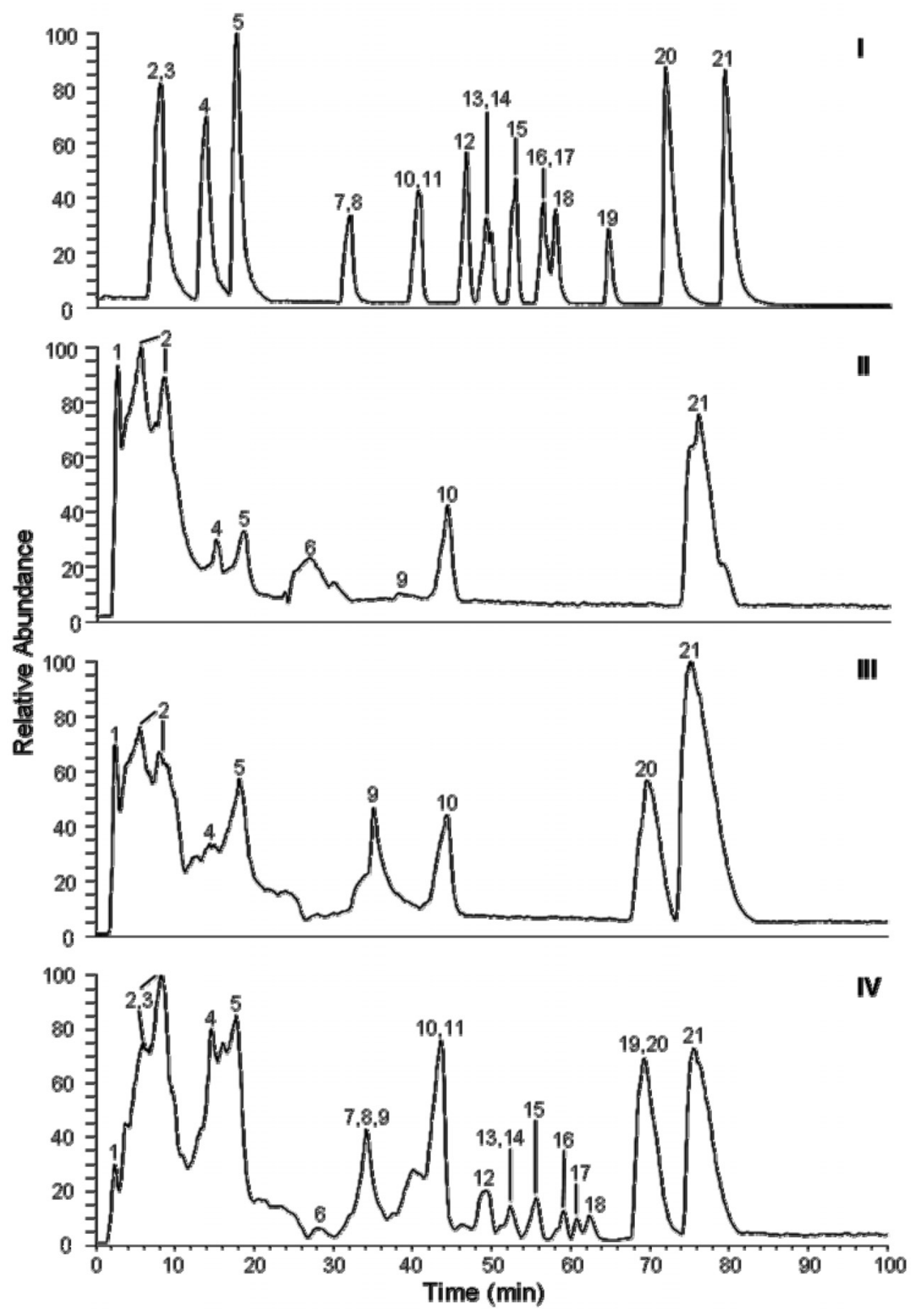

Figure 1. HILIC-ESI-MS base peak chromatograms for HILIC Column 2. I: Reference mixture, II: water-soluble extract of Cheese A, III: water-soluble extract of Cheese B, IV: water-soluble extract of Cheese B spiked with the reference mixture. Peak identification; 1: m/z 168, 2: Leu/Ile, 3: Trp-Gly-Tyr, 4: Val; 5: Pro, 6: m/z 105, 7: Ser, 8: Asn, 9: m/z 156, 10: Glu, 11: Asp, 12: Glu-Ala, 13: Thr-Glu, 14: Glu-Ser, 15: Ala-Glu, 16: Gly-Glu, 17: Glu-Asp, 18: Asp-Glu, 19: Glu-Glu-Glu, 20: Arg, 21: Lys. Identification based on MS/MS and $\mathrm{MS}^{3}$ spectra. 
patterns depending on the position of the glutamyl residue and an unambiguous identification is therefore possible, as shown by Schlichtherle-Cerny et al. [19] for the glutamyl dipeptides with Thr, Ser and Lys. In this study the unique MS/MS and $\mathrm{MS}^{3}$ spectra for Glu-Ala, Ala-Glu and Glu-Asp, Asp-Glu are shown in Figure 2.

The MS/MS spectra of the parent ion $\mathrm{m} / \mathrm{z} 219[\mathrm{M}+\mathrm{H}]^{+}$for the dipeptides GluAla and Ala-Glu both showed a product ion of $\mathrm{m} / \mathrm{z} 201$, which was generated by the loss of a water molecule. The $\mathrm{MS}^{3}$ spectrum of Glu-Ala led to an unambiguous identification based on the intense signal of $\mathrm{m} / \mathrm{z} 90$, resulting from the $\mathrm{C}$-terminal Ala residue. Additional intense ions in the $\mathrm{MS}^{3}$ spectrum were $\mathrm{m} / \mathrm{z} 183$, due to the loss of a second water molecule, and $\mathrm{m} / \mathrm{z} 155$, which indicates the loss of two water molecules and a carbon oxide molecule from the parent ion $\mathrm{m} / \mathrm{z} 201$. On the other hand, fragmentation of the reversed analogue Ala-Glu was dominated by the unique ion $\mathrm{m} / \mathrm{z} 148$ in the MS/MS spectrum, corresponding to the C-terminal glutamyl residue. These specific fragmentation patterns made an unequivocal identification of the reversed analogues possible. Similar characteristic ion patterns were detected for the pair of Glu-Asp and AspGlu. The $\mathrm{MS}^{3}$ spectrum for Glu-Asp revealed the ion $\mathrm{m} / \mathrm{z} 134$ for the $\mathrm{C}$-terminal Asp residue. In the MS/MS spectrum AspGlu gave rise to the characteristic ion $\mathrm{m} / \mathrm{z} 148$ from the C-terminal glutamyl residue, which led to unambiguous identification. However, this signal was less intense as compared with the more dominating ions $\mathrm{m} / \mathrm{z} 245$ and $\mathrm{m} / \mathrm{z} 227$, related to the losses of one and two water molecules, respectively. Unique for Asp-Glu was also the intense ion $\mathrm{m} / \mathrm{z} 185$ in the $\mathrm{MS}^{3}$ spectrum, corresponding to the additional loss of $\mathrm{CH}_{2} \mathrm{CO}$, indicating fragmentation of the amino acid side chains.

According to the results of the present study only the $\mathrm{MS}^{3}$ spectra allowed an un- ambiguous identification of the $\mathrm{N}$-terminal glutamyl peptides, whereas MS/MS was sufficient for the identification of the $\mathrm{C}$ terminal glutamyl peptides.

\subsection{Analysis of mature Cheddar cheese}

The water-soluble extracts of two mature Cheddar cheeses, selected because of their pronounced savoury flavour, were analysed by applying the described HILICESI-MS method (Fig. 1). According to the reference mixture the potentially tasteactive glutamyl di- and tripeptides of interest should elute in the time frame of 45 to $65 \mathrm{~min}$ but no peaks occurred in the chromatograms for the mature Cheddar cheeses in this interval. As a result, it could be concluded that the hydrophilic di- and tripeptides of the reference mixture were not present in the extracts of the two mature Cheddar cheeses. It has to be taken into account that the hydrophilic peptides could be present at concentrations below their limit of detection. The reference mixture, however, contained glutamyl peptides at a concentration of $0.25 \mathrm{~g} \cdot \mathrm{L}^{-1}$, which is close to the taste thresholds reported in the literature for these peptides $[2,15,16$, 23]. Therefore, it was expected that hydrophilic peptides in the Cheddar cheese extracts would show relatively intense signals if they should contribute to the perceived savoury flavour. On the other hand, amino acids dominated the water-soluble extracts and eluted in the order of Leu/Ile, Val, Pro, Glu, Arg and Lys, corresponding to the results obtained for the reference mixture. The chromatograms also revealed several dominating ions that could not be assigned to amino acids or peptides.

The ability of the HILIC method to analyse hydrophilic di- and tripeptides in the relatively crude and complex watersoluble Cheddar cheese extracts was verified by spiking the samples with the 
MS/MS
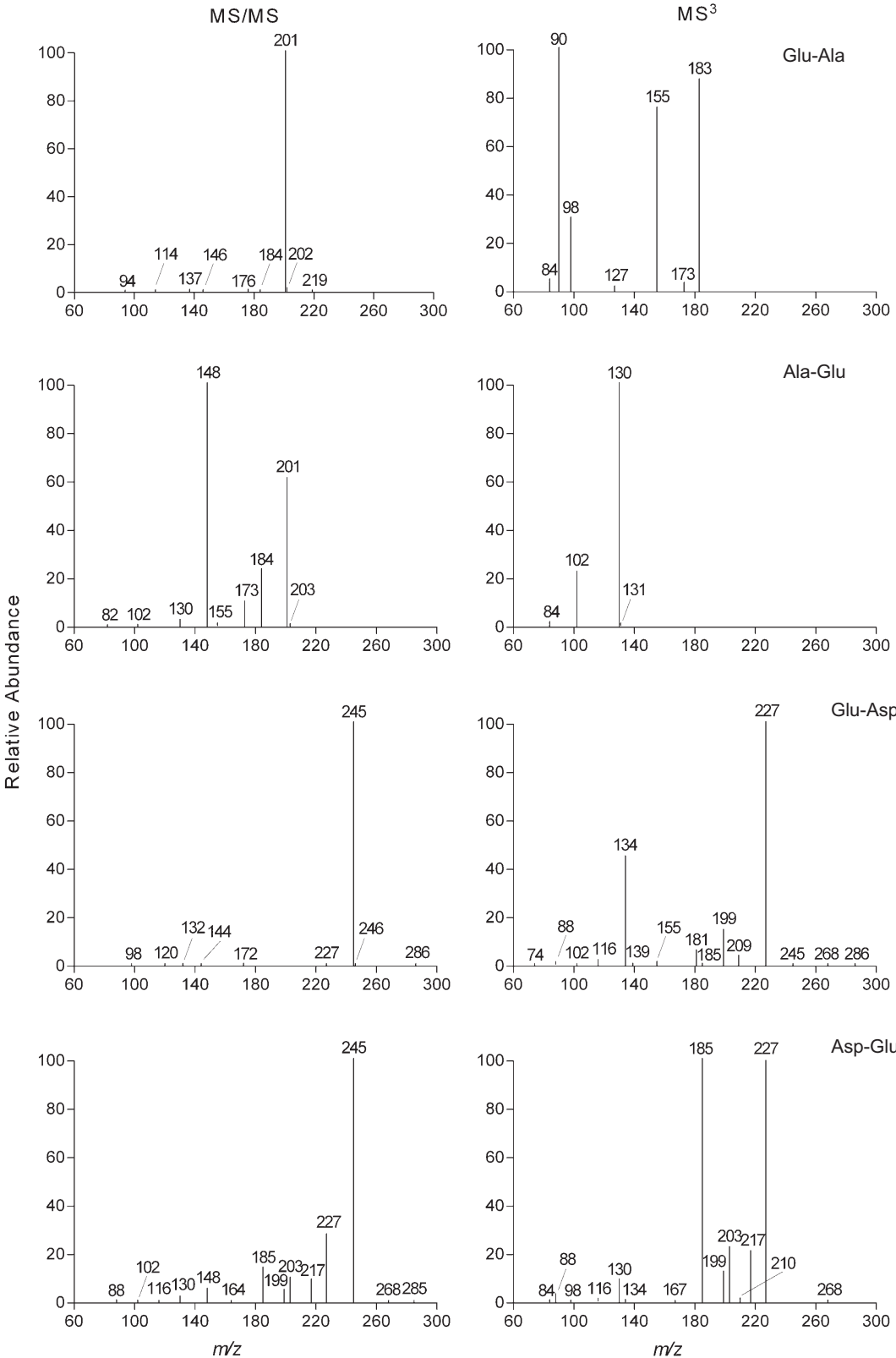

Figure 2. MS/MS and $\mathrm{MS}^{3}$ spectra of the isobaric glutamyl peptides Glu-Ala, Ala-Glu and GluAsp, Asp-Glu, respectively. 
reference mixture. The low-molecularweight peptides were added at concentrations close to their reported thresholds [2, $15,16,23]$. The base peak chromatogram revealed clear signals for the relevant di- and tripeptides from the reference mixture and the elution order was consistent with that for the pure reference mixture, but differences in retention time for the compounds were observed (Fig. 1). To ensure that the hydrophilic low-molecular-weight peptides were not lost by the ultra-filtration, the unfiltrated water-soluble extracts were analysed. Identical results were obtained and no glutamyl di- or tripeptides were identified (data not shown).

Potentially umami taste-active peptides have been reported in the literature for Parmesan and Comté cheese [18, 19]. Peptides such as Glu-Gly, Glu-Ser, Glu-Glu, Glu-Arg, $\gamma$-Glu-Leu and $\gamma$-Glu-Tyr were identified. The peptides were linked to the degradation of casein but not to the taste properties of the cheeses. In spite of the pronounced savoury flavour in the selected mature Cheddar cheeses, none of the alleged taste-active hydrophilic glutamyl peptides were identified. The two mature Cheddar cheeses were ripened for 12 and 10 months, respectively, and during manufacturing a ripening culture was added to the latter to accelerate amino acid release. Low-molecular-weight peptides are a result of peptidolytic activity, and their accumulation in cheese depends on a dynamic balance between formation and degradation. During ripening some peptides with specific properties accumulate in the cheese as a consequence of limited enzymatic activity towards these peptides that typically are highly basic, and contain phosphate groups or the secondary amino acid Pro. Small hydrophilic peptides containing Glu have been reported not to accumulate in Cheddar cheese [9], but are likely to be hydrolysed by the peptidases in the cheese matrix or taken up by lactic acid bacteria [5]. This correlates with the findings in this study.

The HILIC chromatograms revealed the presence of Glu in both Cheddar cheeses (Fig. 1). Glu exhibits the basic taste of umami and could be one of the main contributors to the perceived savoury flavour in the mature Cheddar cheeses. Other compounds reported to exhibit taste activity in relation to umami and savoury are, e.g., amino acids, organic acids and inorganic ions $[8,20,25]$. Future work will focus on quantitative studies as well as investigations of the sensory impact of these compounds on savoury flavour.

In conclusion, the HILIC-ESI-MS method was successfully applied to a reference mixture of amino acids and hydrophilic di- and tripeptides at concentrations close to their reported taste thresholds. Identification of the compounds was based on retention time and fragmentation patterns in MS/MS and $\mathrm{MS}^{3}$. However, no potentially umami taste-active glutamyl di- or tri peptides were identified in the water-soluble extracts from either of the two mature Cheddar cheeses, which were selected because of their pronounced savoury flavour. Consequently, the presence of glutamyl diand tripeptides are not a precondition for savoury flavour in mature Cheddar cheese.

Acknowledgements: The staff at the Swiss Federal Research Stations for Animal Production \& Dairy Products, Agroscope Liebefeld Posieux (ALP) are thanked for making this study possible and for interesting and constructive discussions. The financial support from Chr. Hansen A/S and the Research School for Biotechnology, Faculty of Life Sciences, Copenhagen University is acknowledged.

\section{REFERENCES}

[1] Alpert A.J., Hydrophilic-interaction chromatography for the separation of peptides, nucleic acids and other polar compounds, J. Chromatogr. A 499 (1990) 177-196. 
[2] Arai S., Yamashita M., Noguchi M., Fujimaki M., Taste of L-Glutamyl oligopeptides in relation to their chromatographic properties, Agric. Biol. Chem. 37 (1973) 151-156.

[3] Ardo Y., Gripon J.C., Chromatographic methods used to measure proteolysis in cheese, IDF Bul. 261 (1991) 29-34.

[4] Ardo Y., Mansson H.L., Hedenberg A., Larsson P.O., Studies of peptidolysis during early maturation and its influence on low-fat cheese quality, Milchwissenschaft 44 (1989) 485-495.

[5] Ardo Y., Thage B.V., Madsen J.S., Dynamics of free amino acid composition in cheese ripening, Aust. J. Dairy Technol. 57 (2002) 109-115.

[6] Aston J.W., Creamer L.K., Contribution of the components of the water-soluble fraction to the flavor of Cheddar cheese, N. Z. J. Dairy Sci. Technol. 21 (1986) 229-248.

[7] Cliffe A.J., Marks J.D., Mulholland F., Isolation and characterization of non-volatile flavours from cheese: Peptide profile of flavour fractions from Cheddar cheese, determined by reverse-phase high-performance liquid chromatography, Int. Dairy J. 3 (1993) 379-387.

[8] Drake S.L., Carunchia Whetstine M.E., Drake M.A., Courtney P., Fligner K., Jenkins J., Pruitt C., Sources of umami taste in Cheddar and Swiss Cheeses, J. Food Sci. 72 (2007) S360-S366.

[9] Fernandez M., Singh T.K., Fox P.F., Isolation and identification of peptides from the diafiltration permeate of the water-soluble fraction of Cheddar cheese, J. Agric. Food Chem. 46 (1998) 4512-4517.

[10] Guo Y., Gaiki S., Retention behavior of small polar compounds on polar stationary phases in hydrophilic interaction chromatography, J. Chromatogr. A 1074 (2005) 71-80.

[11] Hemstrom P., Irgum K., Hydrophilic interaction chromatography, J. Sep. Sci. 29 (2006) 1784-1821.

[12] McSweeney P.L.H., The flavour of milk and dairy products: III. Cheese: Taste, Int. J. Dairy Technol. 50 (1997) 123-128.

[13] Mojarro-Guerra S.H., Amado R., Arrigoni E., Solms, J., Isolation of low-molecularweight taste peptides from Vacherin Mont d'Or cheese, J. Food Sci. 56 (1991) 943-947.

[14] Ninomiya K., Natural occurrence, Food Rev. Int. 14 (1998) 177-211.
[15] Noguchi M., Arai S., Yamashita M., Kato H., Fujimaki M., Isolation and identification of acidic oligopeptides occurring in a flavour potentiating fraction from a fish protein hydrolysate, J. Agric. Food Chem. 23 (1975) 49-53.

[16] Ohyma S., Ishibashi N., Tamura M., Nishizaki H., Okai H., Synthesis of bitter peptides composed of aspartic acid and glutamic acid, Agric. Biol. Chem. (1988) 871-872

[17] Roturier J.M., Lebars D., Gripon J.C., Separation and identification of hydrophilic peptides in dairy products using FMOC derivatization, J. Chromatogr. A 696 (1995) 209-217.

[18] Roudot-Algaron F., Kerhoas L., Le Bars D., Einhorn J., Gripon J.C., Isolation of gammaglutamyl peptides from Comte cheese, J. Dairy Sci. 77 (1994) 1161-1166.

[19] Schlichtherle-Cerny H., Affolter M., Cerny C., Hydrophilic interaction liquid chromatography coupled to electrospray mass spectrometry of small polar compounds in food analysis, Anal. Chem. 75 (2003) 23492354.

[20] Schlichtherle-Cerny H., Grosch W., Evaluation of taste compounds of stewed beef juice, Z. Lebensm. Unters. Forsch. A. 207 (1998) 369-376.

[21] Singh T.K., Fox P.F., Højrup P., Healy A., A scheme for the fractionation of cheese nitrogen and identification of principal peptides, Int. Dairy J. 4 (1994) 111-122.

[22] Strege M.A., Hydrophilic interaction chromatography electrospray mass spectrometry analysis of polar compounds for natural product drug discovery, Anal. Chem. 70 (1998) 2439-2445.

[23] Tamura M., Nakatsuka T., Tada M., Kawasaki Y., Kikuchi E., Okai H., The relationship between taste and primary structure of "delicious peptides" (Lys-Gly-Glu-GluSer-Leu-Ala) from beef soup, Agric. Biol. Chem. 53 (1989) 319-325.

[24] Van den Oord A.H.A., van Wassenaar P.D., Umami peptides: assessment of their alleged taste properties, Z. Lebensm. Unters. Forsch. A. 205 (1997) 125-130.

[25] Warmke R., Belitz H.D., Grosch W., Evaluation of taste compounds of Swiss cheese (Emmentaler), Z. Lebensm. Unters. Forsch. 203 (1996) 230-235. 